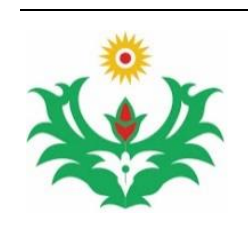

Linguistik Terapan 16 (3) (2019): 586- 596

Jurnal Linguistik Terapan Pascasarjana

Available Online

http://jurnal.unimed.ac.id/2019/index.php/JLT-Unimed

\title{
Modality Used in Beauty Product Advertisements on Instagram Caption
}

\author{
Indri Eka Sari \\ Anni Holila Pulungan \\ Rahmad Husein
}

English Applied Linguistics Program

Postgraduate Program-Universitas Negeri Medan

Diterima September 2019; Disetujui Oktober 2019; Dipublikasikan Desember 2019

\section{ABSTRACT}

This research was carried out to investigate the modality used in beauty product advertisements on Instagram caption. The objective of the research was to describe the types of modality used in beauty product advertisements on Instagram caption. The data of this research was the clauses consisting of modality used in beauty product advertisements which are taken from official account of three local brands on Instagram. Descriptive qualitative method was used in this research. The instrument of this research was observation. The types of modality were analyzed by using the theory of Carrettero (2007). In this research was found four types of modality. The types were found in this research, namely Epistemic, Deontic, Dynamic, and Boulomaic.

Keywords: Types of Modality, Beauty Product Advertisements, Instagram Caption

How to Cite: Ritonga, Siti Rahma (2019). Modality Used in Beauty Product Advertisements on Instagram Caption. Jurnal Linguistik Terapan Pascasarjana Unimed.

ISSN 0216-5139

\section{INTRODUCTION}

Modality as the speaker's judgement of probabilities, or the obligation involved in what is saying. Modality has to do with commitment which covers the speaker's judgement and attitude in presenting his ideas and message in text. Other researcher explored the semantic underpinnings of modal auxiliary verbs. They are used extensively to give the message a sense of intention, promise, obligation and necessity in a conscious and strategic attempt to persuade the electorate. Modality is also evident in the advertisements to give flavor on their purpose. It is realized from the ways of modality in expressing attitudes 
towards a person, a situation or an event, giving opinion about what is to be judged as true, likely or desirable. Several reseachers have ever done relevant studies of modality, language study, and so on. Other investigation about the realization of modality in English which applied in Marhata Sinamot Text. This research found that the expressing modality markers that are identified in the texts understudy are modality markers of probability, obligatoriness, willingness, and usuality. Other research explored modals such as 'will', 'shall', 'must', 'can', etc. are used by the politicians in both manifestoes for persuasion, obligation, to make promises, demonstrate political will/commitment, and solicit public support and manipulation.

Instagram is superior in terms of photo-sharing feature and simplicity or directness in providing visualized descriptions about products. It will help the company to promote the products in an efficient and interesting way. In advertising phenomenon nowadays, the companies have the official account in Instagram and they are going to be some of the favorite following accounts listed for Instagram users. Beauty product is one kind of advertisements which has ranked as popular industry in the global market place. The use of Instagram helps the beauty product company to complete their arrival product with photo and caption below the picture. Caption is the part of legal document that the beauty product companies attach the caption below the picture of product they advertised in their officially Instagram account.

In fact, the message is delivered in beauty product advertisements often not appropriate with the result. Advertisements language always seems interesting to take people's attention in purchasing the products. But it doesn't always help the women to get satisfied of the products. It is caused some reasons like the texture of product is not like what they expected, their face get breakout or pimples, their skin will be dry and they do not look better with the product. Because of these problems that happen around women especially in beauty products make them hard to believe the advertisements, they will not be interested to the advertisements which applied by the company.

Related to the matters above, the researcher found that beauty product brands make their caption into English and almost use modality in all their posts. The company creates the persuading language through modality to give more taste and good possibility that customers will get from their products. The use of modality in Instagram caption available in some brands of beauty product helps to express what is, what would be, what may be and what should be. The evident of modality can be seen in beauty product advertisements on their official account, for instance: 


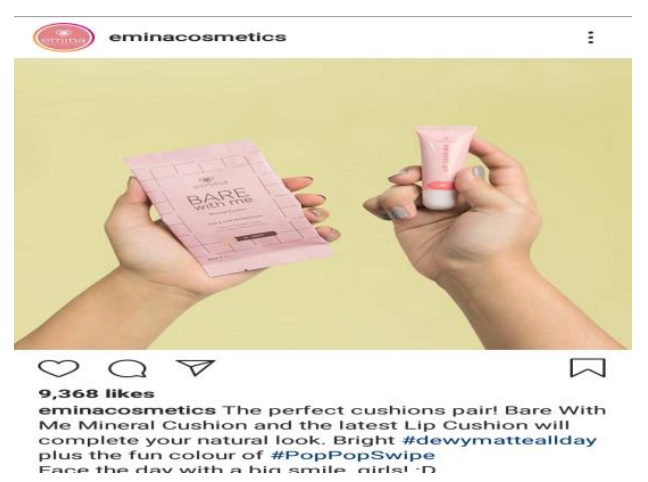

The caption in the advertisement above states modal auxiliary word "will'." Bare With Me Mineral Cushion and the latest Lip Cushion will complete your natural look”.

The modal word in the caption is categorized as possibility or probability because it provides with the truth of a preposition related to the writer's knowledge and belief. The modality "will" emphasizes if women touch up their face using Bare With Me Mineral Cushion and the latest Lip Cushion from Emina cosmetic, it is possible to make their look be natural and fresh. It can be looked like they do not need more powder apply or too much make up look. It is able to take women' attention that Emina is the right decision to choose as their daily cosmetic tool. Moreover nowadays, natural make up look like Korean is being a trend and a necessity for women than make up with bold look. Natural look makes their truly charm appears.

Modality refers to the expectation or point of view of the speaker or writer through the content of the clause. The function of modality is to express "the attitude of the speaker towards the utterance, according to whether it is considered a fact, a belief, a necessity, etc." and every language has its expressive ways in using this aspect [7]. Classifying modal auxiliary verbs may function in more than one category, for instance, explains that 'can' conveys permission in the structure, "John can come in now", but conveys ability in the sentence, “John can speak French" [8].

Modality are divided into four types, they are Epistemic, Deontic, Dynamic and Boulomaic [9]. Epistemic is defined to do with the difference of probability degree. Deontic concerns the difference of obligation degrees. Dynamic is referred to the different degree of predisposition (ability-tendency). Boulomaic which concern the different degree of volition or wish. Modality may be expressed in the clause through certain types of main verbs as well as through adjectives, adverbs and certain nominalizations [10]. Modal auxiliaries are the most common using to the realization of modality. There are some top modal auxiliaries that 
are used to express modality, namely can, could, may, might, shall, should, will, would, and must.

Modalities consist of modalization and modulation. Modalization associated with the author's assessment of the validity of the proposition includes the probability scale. Modalization defines two kinds of meanings. They are probability and usuality [11]. Modulation is defined as the way for speakers to express their judgements or attitudes about actions and events. It is said that when someone is acting for other people, he/she does not only have dogmatic choices of do or don't. In between two poles of compliance and refusal she/he can express degrees their judgement of obligation and inclination [12].

\section{METHODOLOGY}

This research was used descriptive qualitative. Qualitative analysis was applied to find out theoritically about the effect of modality used in beauty product advertisements on Instagram caption.

The data were the clauses consisting of modality in 30 captions of beauty product advertisements which are taken from official account of three local brands on Instagram by using purposive sampling. The source of data is taken from online advertisements on Instagram. The reseacher chose these three brands because some of the criteria, namely they are the top three highest followers for local brand beauty product on Instagram, post the products regularly, the advertisments use English and have the variation products.

\section{FINDINGS AND DISCUSSION}

The researcher found four types of modality in beauty product advertisements on Instagram caption, namely Epistemic, Deontic, Dynamic, and Boulomaic. Specifically, 37\% for Epistemic, 33\% for Deontic, 27\% for Dynamic, and 3\% for Boulomaic. There were three brands of beauty product was taken namely Emina, Pixy and Make Over.

The realization of modality found in beauty product advertisements on Instagram caption consisted of modal auxiliary verbs (will, would, can, have to, need to, want to, must, should, and could), negativity modal (won't and can't) and adverbs (always, never, perfectly, and easily), while there was different way in realizing modality which some clauses realized double modality namely modal auxiliary verbs and modal auxiliary adverbs in one clause. In this study, it was found $74 \%$ used modal auxiliary verbs as the most commonly used and adverbs with $6 \%$ and the researcher was found another way in realizing modality beside the 
common one, there were there were $20 \%$ used combination of modal auxiliary verbs and adverbs between modal verb and adverb in one clause as the new findings. In this case, it expressed to upgrade the certainty and belief of the writer's judgment.

The reason of modality realized in beauty product advertisements on Instagram caption namely modalization and modulation to describe the meanings are delivered in the clause of advertisements. It was consisted $73 \%$ of modalization with $53 \%$ of probability meaning and $20 \%$ of usuality meaning and $27 \%$ consisted modulation with $20 \%$ of obligation meaning and $7 \%$ of inclination meaning. Modality was the secret ingredient to fluent business that important to train the company's market in getting their target. It was able to express the writer's judgment in advertising and give certain explanation about what true or not that would be affected through using their beauty products.

\section{Types of Modality}

There were four concepts of modality were used in beauty product advertisements, namely Epistemic, Deontic, Dynamic, Boulomaic.

\section{Table 1}

\section{Types of Modality Used in Beauty Product Advertisements}

\begin{tabular}{clcc}
\hline No. & $\begin{array}{r}\text { Types of } \\
\text { Modality }\end{array}$ & Number of Clauses & $\begin{array}{c}\text { Percentages } \\
(\%)\end{array}$ \\
\hline 1. & Epistemic & 11 & 37 \\
2. & Dynamic & 10 & 33 \\
3. & Deontic & 8 & 27 \\
4. & Boulomaic & 1 & 3 \\
\hline
\end{tabular}

In this study, the researcher found four types of modality in the clause of advertisements, there were 11 data for Epistemic (37\%), 10 data for Dynamic (33\%), 8 data for Deontic (27\%), and 1 data for Boulomaic (3\%). Types of modality especially Epistemic were using the most to show the possibility of the writer's degree of force or certainty concerning his opinion of the product. In fact, the used of modality in beauty product advertisements is more frequently used to achieve specific communication intents and very useful persuasive strategy.

\section{A. Epistemic}

\section{Data 2}




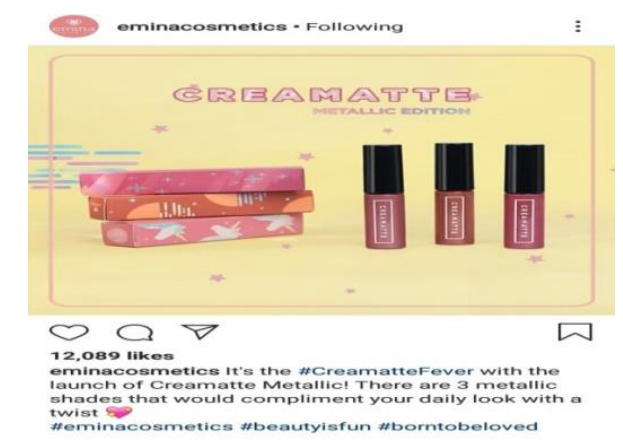

".......There are 3 metallic shades that would compliment your daily look with a twist."

In data 2 , the modal auxiliary 'would' to show prediction or possibility meaning that opinion wrote by the writer will be likely to happen. In the epistemic type, it is used to express what we believe or guess to be true. The use of modal 'would' in that sentence shows the follower that the writer have a high confidence in their product which is lip creamatte with three metallic shades truly make woman who use one of these shades get the lovely compliment from others. The writer believes one of colors their creamatte the woman touch on her lip, her daily look become unusual prettier.

\section{B. Deontic}

Data 12

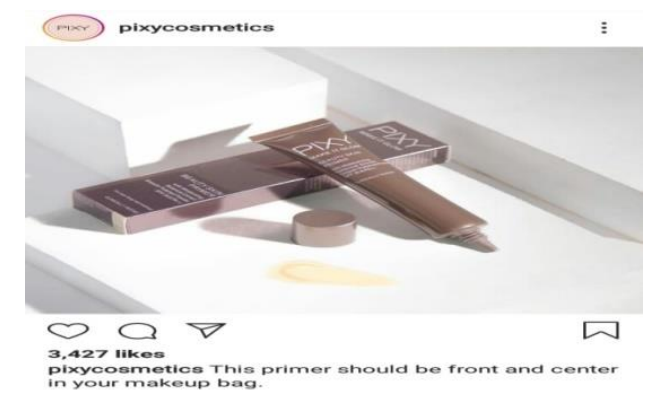

"This primer should be front and center in your make up bag."

From the data above, 'should' is mostly used to say an obligation. The writer states that primer is important to have for woman as the main stuff in make up. The use of modal 'should' in this caption expresses how necessary and good their products, especially primer. Primer is the first thing to apply in the face before starting the next steps, it is used as make up based.

\section{Dynamic}

Data 13 


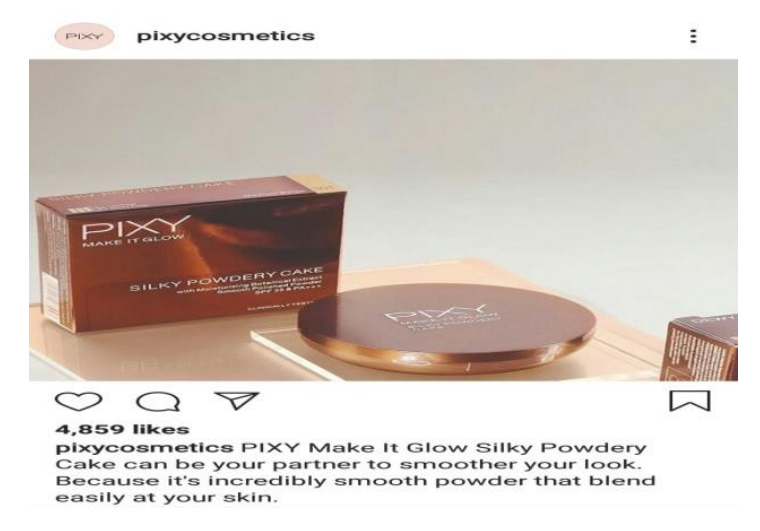

"PIXY Make It Glow Silky Powdery Cake can be your partner to smoother your look."

The modal of 'can' here, the writer feels something that their product is able to work well for customers' look. In addition they can convey the strength of this attitude. In this data, the meaning of 'can' is restricted to the ability meaning. The writer believes that the substance in their product, especially powder, make a flawless and natural look blended with the skin. It explains more that their product is a good choice to have.

\section{Boulomaic}

Data 28

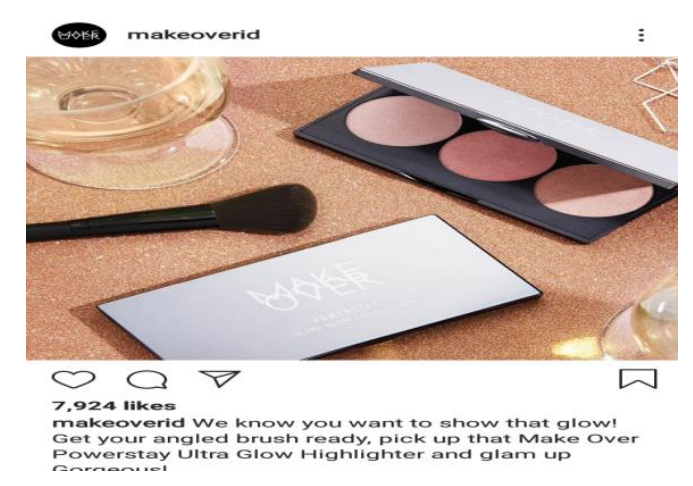

"We know you want to show that glow! Get your angled brush ready, pick up that Make Over Powerstay Ultra Glow Highlighter and glam up Gorgeous!"

Based on the data above, the modal 'want to' express the meaning of inclination. The writer seems knowing what every woman are expected. It takes women' agreement toward the statement that product Highlighter is functioned to give glowing impression in the certain sides of the face. The modal 'want to' here helps to persuade the woman purchasing this product because understanding the final make up look like women want. 


\section{Process of Modality}

Modality used in beauty product advertisements on Instagram caption can be realized in adjectives, adverbs and certain nominalizations. It expressed probability, obligation, willingness, and usuality. In this study, modal auxiliaries were the most common using to the realization of modality in beauty product advertisements. There were some top modal auxiliaries are used, such as will, would, can, have to, need to, want to, must, should, and could. Absolutely, won't and can't as negativity modal was proved and also some adverbs, namely always, never, perfectly, and easily.

It was found 22 data (74\%) used modal auxiliary verbs and the used of will was 6 data $(20 \%)$ as the most frequently used to express the possibility and followed adverbs with 2 data $(6 \%)$ and the researcher found the realization of modality in different way, there were 6 data used combination of modal auxiliary verbs and adverbs (20\%) as the new findings. The realization of more than one modality in one clause called double modality. Here, some examples of realization modality.

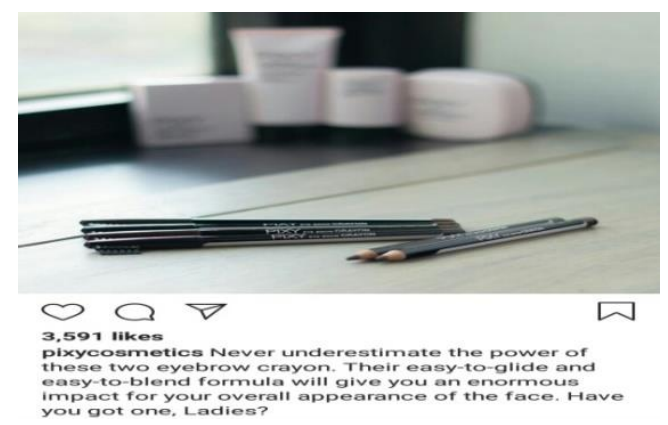

"Never underestimate the power of these two eyebrow crayon. Their easy-to-glide and easy-to-blend formula will give you an enormous impact for your overall appearance of the face."

Eyebrow crayon is the product that applying color to the eyebrows. It is used to fill in and define the eyebrows. This clause realized modal auxiliary verbs will to give possibility influencing the good look of our make-up if we use the eyebrow crayon from their brand.

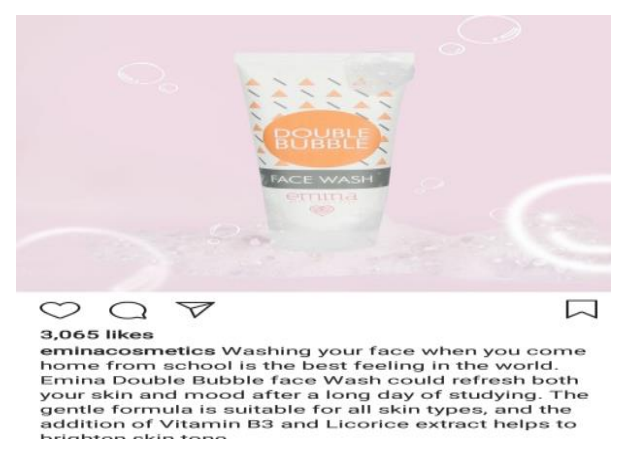


"Emina Double Bubble Face Wash could refresh both your skin and mood after a long day of studying."

Toward this caption, the realizing of modal auxiliary verb could showed that their face wash contains the ingredients that able to make our skin be fresh after doing some activities outside all day and boost our mood cheerfully.

\section{Reasons of Modality}

As one of the realizations of interpersonal function based on the analysis of the data that had been obtained in this study, it divided modality into modalization and modulation.

The researcher found 16 data $(53 \%)$ is contained modalization in probability meaning. It could be seen that modalization was the most commonly used in the beauty product advertisements. Modalization indicated the meaning of the speaker/writer's judgment on the truth of the propositions they wrote. The writer used modalization to make judgments about possibility or usuality of an entire preposition. Beauty product advertisements in this study tended to realize modal auxiliaries such as will, would, can, and could were the frequently ways to convey their opinion. The result showed the writer's lack of confidence in the proposition expressed in their opinion or used as a device for consideration to others.

Table 2. Reasons of Modality

\begin{tabular}{cccc}
\hline \multicolumn{2}{c}{ Reasons } & Frequency & Percentages (\%) \\
\hline \multirow{2}{*}{ Modalization } & Probablity & 16 & 53 \\
& Usuality & 6 & 20 \\
& Obligation & 6 & 20 \\
& Inclination & 2 & 7 \\
\hline \multicolumn{2}{c}{ Total } & 30 & 100 \\
\hline
\end{tabular}

Here are some examples of the clause using modality to express modalization function:

(1) \#PowerPrimeUp with Make Over Powerstay Eye Primer! One swipe will intensify your \#EyesStayStrong colors by thousands. Intensify the power of your stare with this \#MakeOverNewBae Gorgeous!

From the example above, the modal word will expressed probability based on the modalization function. By using this modal, the writer was sure about the result effected from the product and believed the proposition was true. 
(2) Always use Emina Tone Up Cream when you're too lazy to do your make-up before going out.

The modal word always expressed usuality, the writer was believed that the product was functional when we do something regular. There were also some clauses in the beauty product advertisements used modality in relation to show modulation meaning. It was found 8 data $(27 \%)$ were contained with modulation. The meaning of modulation meaning was followed with evidence statements, the writer stated objectively about the function truly effected about the product. Here were some examples of the clause using modality to express modulation meaning:

(3) You have to use both Emina Bright Stuff Face Wash and Moisturizing Cream to make your face healthy and bright.

(4) Refresh and show how healthy skin should look like Gorgeous! Be complexion ready with Make Over Powerskin Water Charge Moisturizer and Make Over Powerstay Weightless

\section{Liquid Foundation.}

From the examples above, the modality word expressed the obligation and inclination about what actions need to perform by addressee based on the writer's perspective. Furthermore, the writer noticed the judgment about how to achieve what we need through applying their product.

\section{CONCLUSION}

Related to the function of modality, it should make sense when the writer actually says, we have to interpret it against the background of what he says. Modality is the secret ingredient to fluent business. In fact, most people do not realize the importance of modality in advertisements. Basically, the work or mean of modality is important for marketing communication to add deeper meaning. Modality is often crucial to talk politely, make request, give suggestion, and set the plan. We absolutely see that the clauses in advertisement as actualized potential and Instagram caption as the platform to express their judgment toward the product to persuade the customer based on the validity of his/her opinion.

\section{REFERENCES}

Halliday, M.A.K. 1994. An Introduction to Functional Grammar Second Edition. London: Edward Arnold.

Nartey, M. 2014. A Semantic Investigation into the Use of Modal Auxiliary Verbs in the 
Manifesto of a Ghanaian Political Party. International Journal of Humanities and Social Science Vol. 4 No 3.

T. Bloner and Sinar L, et al. 2018. Realization and Functional Use of Modality in Marhata

Sinamot Texts. International Journal of Multidisciplinary Research and

Development. Moindjie, M.A. 2015. The Function of Modality in Translation. International Journal of Comparative Literature \& Translation Studies. ISSN 2202-9451.Vol. 3 No. 2.

Universiti Sains Malaysia.

Ehineni, T O. 2014. A Critical Discourse Analysis of Modals in Nigerian Political Manifestos. International Journal of Linguistics Vol 6, No. 3.

Ting, H. and W.P.H. Winni, et.al. (2015). Beliefs about the Use of Instagram: An Exploring Study. International Journal of Business and Innovation. Vol.2. Issue.2.

Vinay, J. and J. Darbelnet. 1958/1995. Comparative Stylistics of French and English:

a Methodology for Translation (J. C. Sager and M. J. Hamel, Trans.). Amsterdam and Philadelphia: John Benjamins Publishing Company.

Palmer, F.R. 2001. Mood and Modality. Cambridge: Cambridge University Press.

Carreretero, M, J.R Zamorano, J.A, Hita, F, Nieto, C. Alonso, and A, Viamil. (2007). An Appoach to Modality for Higher Education Students in English in Marta Genis, Elena Ordura \& David Garcia Ramos (eds). Proceeding of the IV ACLES Conference. Hoyo de Manzaranes: Universidad Antonio de Nebrija.

Fowler, R. 1991. Language in the News: Discourse and Ideology in Press. London and New York: Longman.

Halliday MAK, Matthiessen CMIM. 2014. Halliday's Introduction to Functional Grammar, 4th Edition. London: Routledge.

Eggins, S. 2004. An Introduction to Systemic Functional Linguistics. Second Edition. London: Continuum.

Lyons, J. 1997. Semantics (Vol. 2). Cambridge: Cambridge University Press. 